\title{
Synchronicity in Dry Bulk Shipping Markets: A State-Space Model Approach
}

\author{
Byoung-Wook Ko* $\cdot$ Kyu Ho Kang**
}

\begin{abstract}
This paper investigates synchronicity and idiosyncrasy between the Capesize and Panamax freight rates. To do this, we estimate three dynamic linear models in a state-space model framework including common stochastic trend model, dynamic factor model, and unobserved component model using the data on two dry bulk shipping markets. In particular, the unobserved component model that incorporates both common stochastic trend and common mean-reverting components is newly proposed in this paper. Our estimation results exhibit that the presence of common stochastic trend and cyclical components is significant, indicating strong synchronized dynamics between the Capesize and Panamax freight rates. Furthermore, this paper discusses the parameters instability problem by rolling the estimations whose sample consists of one year daily observations.
\end{abstract}

Key Words : Synchronicity, Dry Bulk Shipping, State-Space Model, Unobserved Component Model, Common Stochastic Trend Model, Dynamic Factor Model

\section{Declarations of interest : none}

\footnotetext{
* Corresponding author: Korea Maritime Institute, valiance@kmi.re.kr, 26, Haeyang-ro 301 beon-gil, Yeongdo-gu, Busan, 49111, Korea, 82-10-4227-5891

** Department of Economics, Korea University

Received June 1, 2021; Received in the 1st revised form June 14 and the 2nd June 24, 2021; Accepted June 29, 2021
} 


\section{Introduction}

The global shipping industry transports over 80 per cent of international trade in physical terms (UNCTAD, 2017). While container shipping provides the transportation services of manufactured cargo, bulk shipping delivers bulk cargoes such as raw material (dry bulk shipping) or oil (wet bulk shipping, i.e., tanker shipping). However, the dry bulk shipping markets can be classified into four subsectors based on the ship sizes. These four dry bulk ships are Capesize, Panamax, Supramax, and Handysize. A Capesize ship, at about 180,000 dead-weight tons (DWT) primarily transports iron ore and coal; a Panamax ship (about 82,000 DWT) transports grain, coal, and iron ore. Because a large portion of the cargoes delivered by each ship (Capesize and Panamax) are the same such as iron ore and coal, their transportation demands co-move. This co-movement of cargo demands causes their freight prices (rates) to move together. The popular BDI (Baltic Dry Index) can be regarded as representing this co-movement in the dry bulk shipping freight markets.

Despite the possibility of synchronicity between the dry bulk shipping markets, however, there are various peculiar factors to each market. For example, due to their deep draught and limited number of commodities that they transport, the operation of Capesize vessels in terms of trading routes and ports they can approach is restricted (Alizadeh and Nomikos, 2010, p.324). That is, Capesize ship is involved in narrower shipping service than other ships. This inflexibility causes high volatility of Capesize market prices (esp., freight rates). In summary, these synchronicity and idiosyncrasy in dry bulk shipping markets should be analyzed simultaneously (e.g., see Ko 2011a, 2011b).

A plausible way to analyze the synchronicity and idiosyncrasy is to assume that there are some common (i.e., synchronistic) and peculiar (i.e., idiosyncratic) factors. As suggested by Kim and Nelson (1999), synchronicity can be captured by common stochastic trends in a non-stationary case or dynamic common factors in a stationary case. The non-stationary common stochastic trend and stationary dynamic factor models can also be constructed in an unobserved (or latent) components (permanent trends plus transitory cycles) model framework. It is important to note that the data generating process with common non-stationary stochastic trends can be represented by a vector error correction model (see Stock and Watson, 1988, and Watson 1994, pp.2870-2876). The presence of cointegrating vectors implies a long-run relationship between the integrated variables, but this approach is not useful for decomposing the variables into common and idiosyncratic components in an orthogonal way.

This paper adopts various dynamic linear models including common stochastic trend model, dynamic common factor model, and unobserved component model in order to quantify the synchronicity and idiosyncrasy in the dry bulk shipping markets. In particular, the unobserved component model 
proposed in this paper is most generalized and novel to the best of our knowledge, as it incorporates both common stochastic trend and common mean-reverting cyclical components. More importantly, it turns out that this model is preferred to the other models. This finding implies that the presence of both common stochastic trend and cyclical components is significant, indicating strong synchronized dynamics between the Capesize and Panamax freight rates. Furthermore, this paper discusses the parameters instability problem by rolling the estimations whose sample consists of one year daily observations. One additional contribution of this paper is to suggest an estimation algorithm for decomposing the non-stationary dry bulk freight rates into common component and idiosyncratic component within the unifying framework.

Numerous previous empirical studies attempt to analyze the unobserved common and peculiar components in various economic variables. In general, common factors are interpreted as aggregate or global events, and the idiosyncratic factors are regarded as variable-specific events. However, the traditional notion of time series econometrics that the unobserved commonality would exist in observed economic realities (or variables) may not be acceptable for non-econometricians. They can argue that the actual existence is indeed the concrete activities (or variables) and thus unobserved commonality is simply an artificial concept for enhancing the understanding of actual concrete phenomena. This hesitation to use virtually unobserved statistical metric is not new. For instance, Stigler (1986) showed that social scientists "tried to overcome the conceptual barrier" in about eighty years during the historical process of regression analysis's (in 1885) following the least squares (in 1805). That is, the simple development from least squares method to regression analysis took about eighty years, which had been due to the difficulty in overcoming the "conceptual barrier" (p.5).

However, whether accepted or not, the aforementioned structural characteristics of dry bulk shipping markets make the Capesize and Panamax comove. Therefore, the mathematical modelling of these markets using common factors enables us to measure their virtual synchronicity and idiosyncrasy in a unified framework. These synchronicity and peculiarity in dry bulk shipping markets motivates this study to scrutinize the markets through the three dynamic linear models. Furthermore, this understanding of the dynamics of freight rates will help the participants in dry bulk shipping markets enhance the management efficiency of their revenues and market risks. For instance, the practical advantages of the state-space models have been demonstrated by policy institutions such as central banks and ministries (Barigozzi, Lippi, and Luciani, 2016a, p.2, 2016b, p.2).

This paper is organized in five sections: Section 2 presents a review of the relevant literature of econometric approaches of dynamic linear model and their applications to dry bulk shipping markets; Section 3 describes the empirical models; Section 4 explains the dataset and the empirical results with discussions; Section 5 concludes by suggesting future research topics. 


\section{Literature Review}

In this section, the two strands of literature are reviewed. One is on the econometric approaches such as dynamic factor, common stochastic trend, and unobserved component models. The other is on the applications of these econometric models to dry bulk shipping markets.

It is known that Geweke (1977) introduced the dynamic factor analysis in econometrics. Compared with the stationary dynamic factor model, there have been numerous attempts to apply the non-stationary common stochastic trend models to economic analyses. Inter alia, Chang, Miller, and Park (2009) extracted a single trend and thus calculated a representative index by using state-space model with Kalman filter, which is a kind of common stochastic trend model. Clark (1987) suggested a well-known unobserved component (non-stationary plus stationary components) model based on univariate time series data and was extended to bivariate cases (Clark, 1989).

However, the approach based on dynamic factor models has become increasingly popular in the econometric analyses. In particular, there have been various efforts to incorporate the non-stationary dynamic factors (whether of common components or of idiosyncratic components) in the dynamic factor models. Barigozzi and Luciani (2017) "first disentangle common and idiosyncratic dynamics by using a Non-Stationary Approximate Dynamic Factor Model and then disentangle common trends from common cycles by applying a nonparametric trend-cycle decomposition to the latent common factors" (p.2). Their key contribution is to "differentiate from the standard state-space approach in which the trend and cycle dynamics are explicitly specified and jointly estimated with the parameters of the model" (p.3). Barigozzi, Lippi, and Luciani (2016a, 2016b) constructed the dynamic factor models where the common factors can be non-stationary and the idiosyncratic components can also be non-stationary. This possibility that the idiosyncratic components can be non-stationary was a crucial differentiation from the previous studies with the idiosyncratic elements stationary (e.g., Bai, 2004 and Peña and Poncela, 2006). Furthermore, these two studies allowed cointegration relationship between the unobserved components.

However, the stability assumption of parameters (e.g., factor loadings in dynamic factor models) in the equations of unobserved components may not be satisfied. If not stable, there could be two forms of parameter instability. One is to have some break points and another is for the parameters to evolve over the considered period. This topic of instability in the parameter values was reviewed briefly in Stock and Watson (2016, pp.437-440). In addition, when the break time is unobserved, popular dynamic linear model with Markov switching regimes could be used in which the so-called Kim filter (Kim, 1994) is known to be reliable and efficient in both of the classical and Bayesian frameworks (see Kim and Kang, 2019).

In shipping literature, there have been various applications of cointegration 
models. Veenstra and Franses (1997) applied a co-integration model to the analysis of relationship between Capesize and Panamax freight markets. Particularly, they used a common stochastic trend approach for forecasting freight rate. Chen, Meersman and Voorde (2010) investigated the interrelationships in daily returns and volatilities between Capesize and Panamax price series in the four major trading routes.

Ko (2010a) applied a dynamic factor model to dry bulk freight markets. To the best of our knowledge, his dynamic factor model using the change rates, not the freight level, is the first attempt to analyze the synchronicity and idiosyncrasy in a unified framework. In addition, this study showed that there had been some structural breaks in the synchronicities of the considered shipping markets. Ko (2010b) analyzed the same dry bulk shipping markets through the lens of a common stochastic trend model. He tried to suggest an alternative method of calculating an index representing a general movement by using the level variables of the dry bulk shipping markets. Furthermore, his lens of common stochastic trend model could decompose the freight data into common (or permanent) and idiosyncratic (or transitory) components.

Recently, there have been some notable studies using dynamic factor model and common trend model. Angelopoulos, Sahoo and Visvikis (2020) analyzed the interrelationships among the commodity, maritime transportation, and financial markets with different frequencies (daily, weekly, and monthly) in a single time series model, i.e., dynamic factor model. Adland, Benth and Koekebakker (2018) modeled the dynamics of ocean freight rates in a cointegrated time series model. These two researches adopted the same perspective of this paper in the sense that there would be some commonalities and idiosyncrasies in the shipping markets.

This paper contributes to the literature in the following three ways. First, this paper confirms the usefulness of dynamic factor model (Ko, 2010a) and common stochastic trend model (Ko, 2010b) in the analysis of synchronicity of dry bulk shipping markets by using more recent data. Second, this study synthesizes the previous dynamic factor model and common stochastic trend model by using an unobserved component model. Third, this paper examines the parameter instability of the underlying model assumed by specified state-space approach, which will trigger future researches to model the dynamics of the considered parameters. In other words, this paper shows the future research direction, for example, to model the dry bulk shipping freight rate movements by using some synthesizing time-varying coefficients unobserved component model.

\section{Methodology}

In this section, first, a representative state-space model is presented and its estimation algorithm is explained briefly. Second, the three state-space models of this paper, that is, common stochastic trend model, dynamic factor model, and unobserved component model will be specified. 


\subsection{Introduction of state-space model and its estimation algorithm using the Kalman filter}

State-space model is a powerful systematic tool, especially for estimating unobserved states from observed data (For more detailed information on the statespace model and its estimation algorithm, see Kim and Nelson, 1999 or the Appendix of this paper). It consists of measurement equation and state (or transition) equation. The second state (or transition) equation specifies the "transition" dynamics of unobserved "state" variables. The first measurement equation links the observed data with the unobserved state variables. One representative state-space model is as follows:

[Measurement Equation]

$\left.y_{t}=H \beta_{t}+E_{t},--1\right)$

[State (or Transition) Equation]

$\left.\beta_{t}=F \beta_{t-1}+V_{t} \cdot---2\right)$

The above state-space model is typically estimated by the Kalman filter (Kalman, 1960), which consists of a prediction step before observing new information and an updating step after observing this new information. In advance of explaining the Kalman filter, we define the notations as follows:

Table 1. Notations for State-Space Model

\begin{tabular}{c|l}
\hline Definition & \multicolumn{1}{c}{ Explanation } \\
\hline$\Psi$ & the information set \\
\hline$\beta_{\mathrm{t} \mid \mathrm{t}-1}=\mathrm{E}\left[\beta_{\mathrm{t}} \mid \psi_{\mathrm{t}-1}\right]$ & $\begin{array}{l}\text { expectation (estimate) of } \beta_{\mathrm{t}}, \\
\text { conditional on information up to } \mathrm{t}-1\end{array}$ \\
\hline $\mathrm{P}_{\mathrm{t} \mid \mathrm{t}-1}=\mathrm{E}\left[\left(\beta_{\mathrm{t}}-\beta_{\mathrm{t} \mid \mathrm{t}-1}\right)\left(\beta_{\mathrm{t}}-\beta_{\mathrm{t} \mid \mathrm{t}-1}\right)^{\prime}\right]$ & $\begin{array}{l}\text { covariance matrix of } \beta_{\mathrm{t}}, \\
\text { conditional on information up to } \mathrm{t}-1\end{array}$ \\
\hline$\beta_{\mathrm{t} \mid \mathrm{t}}=\mathrm{E}\left[\beta_{\mathrm{t}} \mid \psi_{\mathrm{t}}\right]$ & $\begin{array}{l}\text { expectation (estimate) of } \beta_{\mathrm{t}}, \\
\text { conditional on information up to } \mathrm{t}\end{array}$ \\
\hline $\mathrm{P}_{\mathrm{t} \mid \mathrm{t}}=\mathrm{E}\left[\left(\beta_{\mathrm{t}}-\beta_{\mathrm{t} \mid \mathrm{t}}\right)\left(\beta_{\mathrm{t}}-\beta_{\mathrm{t} \mid \mathrm{t}}\right)^{\prime}\right]$ & $\begin{array}{l}\text { covariance matrix of } \beta_{\mathrm{t}}, \\
\text { conditional on information up to } \mathrm{t}\end{array}$ \\
\hline $\mathrm{y}_{\mathrm{t} \mid \mathrm{t}-1}=\mathrm{E}\left[\mathrm{y}_{\mathrm{t}} \mid \psi_{\mathrm{t}-1}\right]$ & forecast of $\mathrm{y}_{\mathrm{t}}$, given information up to time $\mathrm{t}-1$ \\
\hline$\eta_{\mathrm{t} \mid \mathrm{t}-1}=\mathrm{y}_{\mathrm{t}}-\mathrm{y}_{\mathrm{t} \mid \mathrm{t}-1}$ & prediction error \\
\hline $\mathrm{f}_{\mathrm{t} \mid \mathrm{t}-1}=\mathrm{E}\left[\eta_{\mathrm{t} \mid \mathrm{t}-1}^{2}\right]$ & conditional variance of the prediction error \\
\hline
\end{tabular}

Source: Kim and Nelson (1999, p.22)

Based on these notations, we can use the following algorithm (or procedure) until the estimated (hyper-) parameters maximize the natural log likelihood, as follows: 
Figure 1. Flowchart for the Kalman Filter of State-Space Model

$$
\begin{aligned}
& \beta_{0 \mid 0}, P_{0 \mid 0,} \ln L(\theta)=0 \\
& \text { च }
\end{aligned}
$$

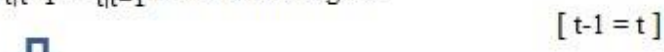

Source: Kim and Nelson (1999, p.26)

Assuming that $H$ is available at the beginning of time $\mathrm{t}$ and a new observation of $\mathrm{y}_{\mathrm{t}}$ is made at the end of time $t$, the Kalman filter consists of the following two steps:

\section{Prediction}

Given the system's dynamics as expressed in Equations 1) and 2), the unobserved variable $\beta_{\mathrm{t}}$ can be predicted by using the information up to the last period. This prediction yields $\beta_{\mathrm{t} \mid \mathrm{t}-1}$, based on which we can predict $\mathrm{y}_{\mathrm{t}}$, which yields $y_{t \mid t-1}$. This process includes two uncertainties: The first is derived from the nature of the unobserved variable, as this variable cannot be directly observed. The second uncertainty is from the disturbance term in the measurement equation. 


\section{Updating}

As the observed variable $\mathrm{y}_{\mathrm{t}}$ is realized, new information becomes available; specifically, the prediction error can be calculated from the realization of $y_{t}$, and this can be used for a more accurate inference of $\beta_{t}$. This updating step uses the so-called "Kalman gain," which is the weight assigned to the new information about $\beta_{\mathrm{t}}$ contained in the prediction error. However, $\beta_{\mathrm{t} \mid \mathrm{t}}$ (the estimate of $\beta_{t}$ ) will be used as an input for the prediction in the next period.

\subsection{Three state-space models}

\subsubsection{Common stochastic trend model}

The first model of this paper is a common stochastic trend model as follows:

$$
\begin{aligned}
& \text { lny } y_{i, t}=\gamma_{i} \times x_{t}+e_{i, t}, e_{i, t} \sim \text { i.i.d.N }\left(0, \sigma_{i}^{2}\right), \\
& x_{t}=x_{t-1}+v_{t}, v_{t} \sim \text { i.i.d.N }\left(0, \sigma_{v}^{2}\right) .
\end{aligned}
$$

In this model, $y$ is the freight rate of considered dry bulk shipping markets. $\ln y_{i, t}$ is influenced by the unobserved non-stationary common stochastic trend $x_{t}$. This trend is assumed to be a random walk process without drift. The influence degree of estimated common stochastic trend on each variable is the coefficient $\gamma_{i}$, which is the measure for synchronicity. The idiosyncrasy is measured by $\sigma_{i}^{2}$. In particular, this common stochastic trend model decomposes the non-stationary (i.e., log-level) data into 1) non-stationary common permanent component $\left(\gamma_{i} \times x_{t}\right)$ and 2) stationary transitory idiosyncratic component $\left(e_{i, t}\right)$. These equations can be represented by the following state-space model:

$$
\begin{aligned}
& \text { [Measurement Equation] } \\
& \widetilde{y_{t}}=H \times \beta_{t}+\widetilde{e_{t}}, \widetilde{e_{t}} \sim \text { i.i.d.N }(0, R), \\
& {[\text { Transition (or State) Equation] }} \\
& \beta_{t}=F \times \beta_{t-1}+\widetilde{v_{t}}, \widetilde{v_{t}} \sim \text { i.i.d.N }(0, Q), \\
& \text { where } \widetilde{y_{t}} \equiv\left(\ln y_{c, t} \ln y_{p, t}\right)^{\prime}, \beta_{t} \equiv x_{t}, \widetilde{e_{t}} \equiv\left(e_{c, t} e_{p, t}\right)^{\prime}, \widetilde{v_{t}} \equiv v_{t}, \\
& H \equiv\left[\gamma_{c} \gamma_{p}\right]^{\prime}, R \equiv\left[\begin{array}{cc}
\sigma_{c}^{2} & 0 \\
0 & \sigma_{p}^{2}
\end{array}\right], F \equiv 1, Q \equiv \sigma_{v}^{2} .
\end{aligned}
$$




\subsubsection{Dynamic factor model}

The second model is a dynamic factor model as follows:

$$
\begin{aligned}
& \Delta \ln y_{i, t}=\alpha_{i} \times c_{t}+e_{i, t}, e_{i, t} \sim \text { i.i.d.N }\left(0, \sigma_{i}^{2}\right), \\
& c_{t}=\emptyset \times c_{t-1}+v_{t}, v_{t} \sim \text { i.i.d.N }\left(0, \sigma_{v}^{2}\right),
\end{aligned}
$$

In this model, $\Delta \ln y_{i, t}$ is the difference of logarithmic values of the freight rates, which is influenced by the unobserved stationary factor $c_{t}$. This common factor is assumed to be an autoregressive process of order 1 whose parameter is $\emptyset$. The influence degree of estimated common dynamic factor on each variable is the coefficient $\alpha_{i}$. which is the measure for synchronicity. The idiosyncrasy is measured by $\sigma_{i}^{2}$. In particular, this dynamic factor model decomposes the stationary (log-differenced) data into 1) stationary common component $\left(\alpha_{i} \times c_{t}\right)$ and 2) stationary idiosyncratic component $\left(e_{i, t}\right)$. These equations can be represented by the following state-space model:

[Measurement Equation]

$$
\widetilde{y_{t}}=H \times \beta_{t}+\widetilde{e_{t}}, \widetilde{e_{t}} \sim \text { i.i.d.N }(0, R),
$$

[Transition (or State) Equation]

$$
\beta_{t}=F \times \beta_{t-1}+\widetilde{v_{t}}, \widetilde{v_{t}} \sim \text { i.i.d.N }(0, Q) \text {, }
$$

where $\widetilde{y_{t}} \equiv\left(\Delta \ln y_{c, t} \Delta \ln y_{p, t}\right)^{\prime}, \beta_{t} \equiv c_{t}, \widetilde{e_{t}} \equiv\left(e_{c, t} e_{p, t}\right)^{\prime}, \widetilde{v_{t}} \equiv v_{t}$,

$$
H \equiv\left[\alpha_{c} \alpha_{p}\right]^{\prime}, R \equiv\left[\begin{array}{cc}
\sigma_{c}^{2} & 0 \\
0 & \sigma_{p}^{2}
\end{array}\right], F \equiv \emptyset, Q \equiv \sigma_{v}^{2} .
$$

\subsubsection{Unobserved component model}

The third model is an unobserved component model as follows:

$$
\begin{aligned}
& \ln y_{i, t}=\gamma_{i} \times x_{t}+\alpha_{i} \times c_{t}+e_{i, t}, e_{i, t} \sim \text { i.i.d.N }\left(0, \sigma_{i}^{2}\right), \\
& x_{t}=x_{t-1}+v_{x, t}, v_{x, t} \sim \text { i.i.d.N }\left(0, \sigma_{v, x}^{2}\right), \\
& c_{t}=\varnothing \times c_{t-1}+v_{c, t}, v_{c, t} \sim \text { i.i.d.N }\left(0, \sigma_{v, c}^{2}\right),
\end{aligned}
$$

In this model, $\ln y_{i, t}$ is influenced by the unobserved non-stationary (permanent) stochastic trend $x_{t}$ and stationary (transitory) factor $c_{t}$. The 
permanent trend is assumed to be a random walk process without drift and the stationary factor to be an autoregressive process of order 1 . The influence degree of estimated common stochastic trend and dynamic factor on each variable are the coefficients $\gamma_{i}$ and $\alpha_{i}$ which are the measures for synchronicity, respectively. The idiosyncrasy is measured by $\sigma_{i}^{2}$. In particular, this unobserved component model decomposes the non-stationary (i.e., log-level) data into 1) non-stationary common permanent component $\left(\gamma_{i} \times x_{t}\right)$ and 2) stationary common transitory component $\left(\alpha_{i} \times c_{t}\right)$ and 3$)$ stationary idiosyncratic component $\left(e_{i, t}\right)$. These equations can be represented by the following state-space model:

[Measurement Equation]

$$
\widetilde{y_{t}}=H \times \beta_{t}+\widetilde{e_{t}}, \widetilde{e_{t}} \sim \text { i.i.d.N }(0, R),
$$

[Transition (or State) Equation]

$$
\beta_{t}=F \times \beta_{t-1}+\widetilde{v_{t}}, \widetilde{v_{t}} \sim \text { i.i.d.N }(0, Q),
$$

where $\widetilde{y_{t}} \equiv\left(\ln y_{c, t} \ln y_{p, t}\right)^{\prime}, \beta_{t} \equiv\left(x_{t} c_{t}\right)^{\prime}, \widetilde{e_{t}} \equiv\left(e_{c, t} e_{p, t}\right)^{\prime}, \widetilde{v_{t}} \equiv\left(v_{x, t} v_{c, t}\right)^{\prime}$,

$$
H \equiv\left[\begin{array}{ll}
\gamma_{c} & \alpha_{c} \\
\gamma_{p} & \alpha_{p}
\end{array}\right], R \equiv\left[\begin{array}{cc}
\sigma_{c}^{2} & 0 \\
0 & \sigma_{p}^{2}
\end{array}\right], F \equiv\left[\begin{array}{ll}
1 & 0 \\
0 & \emptyset
\end{array}\right], Q \equiv\left[\begin{array}{cc}
\sigma_{v, x}^{2} & 0 \\
0 & \sigma_{v, c}^{2}
\end{array}\right] .
$$

\section{Empirical Results and Discussions}

\subsection{Data}

This study uses the dataset consisting of the daily freight rates of Capesize and Panamax markets. In particular, as of 2021, one of the representative freight indicators for Capesize $(18,000$ DWT) is the 5TC average of the five routes for BCI (Baltic Capesize Index) produced by Baltic Exchange and for Panamax $(82,000$ DWT) is the 5TC average for BPI (Baltic Panamax Index). These data are all spot rates representing the current price for transporting dry bulk cargoes. The sample period ranges from $11^{\text {th }}$ November 2017 to $20^{\text {th }}$ May 2021. So, the number of observations is 885 . 
Table 2. Summary of Dataset

\begin{tabular}{c|c|c}
\hline- & Capesize & Panamax \\
\hline Definition of variable & $\begin{array}{c}\text { Average of the } 5 \mathrm{~T} / \mathrm{C} \\
\text { Routes for BCl }\end{array}$ & $\begin{array}{c}\text { Average of the } 5 \mathrm{~T} / \mathrm{C} \\
\text { Routes for BPI-82 }\end{array}$ \\
\hline Sample period & $11^{\text {th }}$ November 2017 to 20 $20^{\text {th }}$ May 2021 \\
\hline Number of observations & \multicolumn{2}{|c}{885} \\
\hline
\end{tabular}

Source: Clarksons

Figure 2 shows the movements of the Capesize 5TC and Panamax 5TC averages. As seen in this figure, there is some high correlations. The correlation is 0.68 in the level case and 0.30 in the log-difference case (Table 3 ). In addition, the determination coefficient $\left(R^{2}\right)$ of the regression from Panamax variable on Capesize variable is 0.88 , which means that the two variables are highly correlated.

Figure 2. Movements of Capesize 5TC and Panamax 5TC Averages

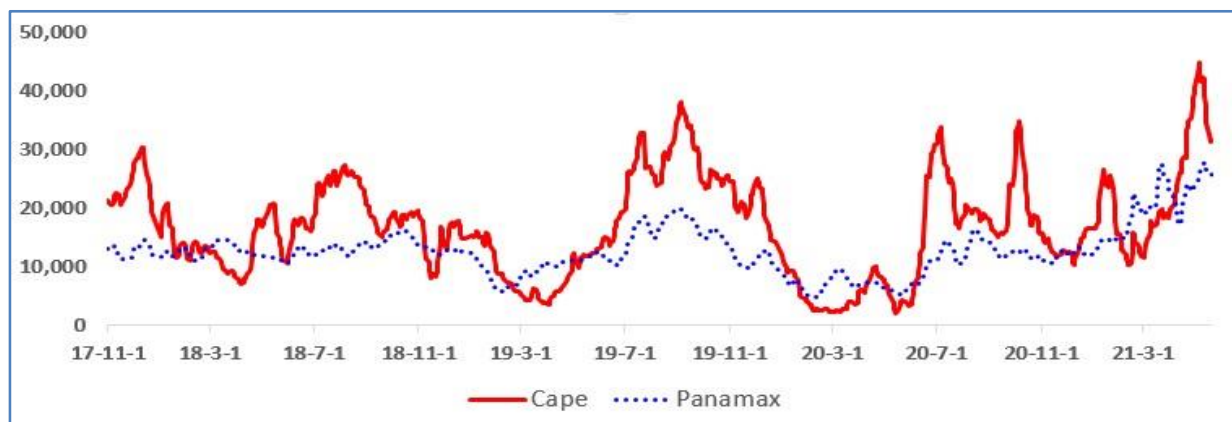

Source: Clarksons

Table 3. Descriptive Statistics

\begin{tabular}{c|c|c|c}
\hline \multirow{2}{*}{ Level } & Mean & Capesize & Panamax \\
\hline \multirow{4}{*}{ Log-differenced } & Standard deviation & 8,544 & 12,740 \\
\cline { 2 - 4 } & Correlation & \multicolumn{2}{|c}{0.68} \\
\cline { 2 - 4 } & Mean & 0.0004 & 4,174 \\
\cline { 2 - 4 } & Standard deviation & 0.0651 & 0.0008 \\
\cline { 2 - 4 } & Correlation & \multicolumn{2}{|c}{0.30} \\
\hline
\end{tabular}


All the values of original data are transformed into natural logarithms. Table 4 shows the unit root test results for checking the stationarity of the variables. For the log-level data, the null hypothesis is that a unit root exists in the case without a constant or trend. If it cannot be rejected at some significance level, then this means that the log-level variables are likely to be non-stationary. This nonstationarity enables us to adopt the stochastic permanent trend model. In addition, for the log-differenced data, the null hypothesis of the existence of unit root in the case without a constant or trend can be rejected at $1 \%$ significance level. This means that log-differencing the non-stationary variables makes them stationary. Therefore, this paper uses these stationary variables in the dynamic factor model.

Table 4. Results of unit root test for the log-level and log-differenced data

\begin{tabular}{|c|c|c|c|}
\hline \multirow{4}{*}{ Capesize } & \multirow{2}{*}{ Log-level } & $\mathrm{t}$-value & -0.045 \\
\hline & & $p$-value & 0.667 \\
\hline & \multirow{2}{*}{ Log-differenced } & t-value & -14.742 \\
\hline & & $p$-value & $0.000^{* * *}$ \\
\hline \multirow{4}{*}{ Panamax } & \multirow{2}{*}{ Log-level } & t-value & 0.318 \\
\hline & & $\mathrm{p}$-value & 0.777 \\
\hline & \multirow{2}{*}{ Log-differenced } & $\mathrm{t}$-value & -10.441 \\
\hline & & p-value & $0.000^{* * *}$ \\
\hline
\end{tabular}

Note: 1$)^{*},{ }^{* *},{ }^{* * *}$ indicate significance at $10 \%, 5 \%, 1 \%$ level, respectively.

2) The t-statistic refers to the Augmented Dickey-Fuller test statistic. Refer to Dickey and Fuller $(1979,1981)$.

3) For the log-level and log-differenced data, the test does not have a constant or trend.

4) The $p$-value implies MacKinnon's (1996) one-sided $p$-value.

5) The values less than $1 / 1000$ are dropped.

In order to apply the "common" stochastic trend model, there should be a cointegration relationship between the variables, the existence of which implies there is a common non-stationary stochastic trend. Table 5 shows that there is a cointegration relationship as predicted by the aforementioned structural characteristics of Capesize and Panamax freight markets. Its p-value is small enough to infer that there would be a cointegration relationship.

Table 5. Results of Cointegration Tests

\begin{tabular}{c|c|c}
\hline- & Trace statistic & -value \\
\hline Number of cointegration Relationship: none & 22.053 & $0.028^{* *}$ \\
\hline Number of cointegration Relationship: at most 1 & 4.965 & 0.287 \\
\hline Cointegrating vector $\left[\begin{array}{ccc}1 & \beta & c\end{array}\right]$ such that \\
$\left.\left[\begin{array}{lll}1 & \beta & c\end{array}\right]\left[\begin{array}{c}c_{t-1} \\
P_{t-1} \\
1\end{array}\right]\right)$ & {$\left[\begin{array}{ll}1-1.826 & 7.603\end{array}\right]$} \\
\hline
\end{tabular}

Note: 1) ${ }^{* *}$ indicate significance at $5 \%$ level.

2) For the explanation of the trace statistic, refer to Johansen (1995).

3) The $p$-value means MacKinnon, Haug and Michells (1999) one-sided $p$-value.

4) The values less than $1 / 1000$ are dropped. 


\subsection{Estimation results and discussions}

Table 6 shows the estimation result of common stochastic trend model. For the normalization of model, the variance of the shocks in the state equation $\sigma_{v}^{2}$ is set to be 0.01. Similar to Ko (2010b, p.397), the influence coefficients are statistically significant. It is notable that the variance of idiosyncratic component in Capesize market $\left(\sigma_{c}^{2}\right)$ is very close to zero, which means that the unobserved common stochastic trend is estimated as close to the dynamics of Capesize variable. However, the two synchronicities of Capesize and Panamax $\left(\gamma_{c}\right.$ and $\left.\gamma_{p}\right)$ are very similar.

Table 6. Estimation Result of Common Stochastic Trend Model

\begin{tabular}{c|c|c}
\hline \multicolumn{3}{c}{$\ln _{i, t}=\gamma_{i} \times x_{t}+e_{i, t}, e_{i, t} \sim$ i.i.d.N $\left(0, \sigma_{i}^{2}\right)$} \\
$x_{t}=x_{t-1}+v_{t}, v_{t} \sim$ i.i.d. $N\left(0, \sigma_{v}^{2}\right)$ \\
\hline- & Estimate & Standard error \\
\hline$\gamma_{c}$ & $0.659^{* * *}$ & 0.015 \\
\hline$\gamma_{p}$ & $0.645^{* * *}$ & 0.015 \\
\hline$\sigma_{c}^{2}$ & 0.000 & - \\
\hline$\sigma_{p}^{2}$ & 0.203 & - \\
\hline
\end{tabular}

Note: ${ }^{* * *}$ indicate significance at $1 \%$ level.

Table 7 shows the estimation result of dynamic factor model. For the normalization of model, the variance of the shocks in the state equation $\sigma_{v}^{2}$ is set to be 0.0001 . As the same as the common stochastic trend model, the two synchronicities of Capesize and Panamax $\left(\alpha_{c}\right.$ and $\left.\alpha_{p}\right)$ are very similar. However, the variance of idiosyncratic component in Panamax market $\left(\sigma_{p}^{2}\right)$ is very close to zero, which means that the unobserved dynamic factor is estimated as close to the dynamics of Panamax variable. In addition, it is notable that the persistence degree of the autoregressive process of unobserved dynamic factor, $\varnothing$ is 0.866 , which is lower than in the unobserved component model of Table 8 . However, the value of 0.866 means that the yesterday's common factor influences today's factor by this magnitude, 0.866 . 
Table 7. Estimation Result of Dynamic Factor Model

\begin{tabular}{c|c|c}
\hline \multicolumn{3}{c}{$\Delta \operatorname{lny}_{i, t}=\alpha_{i} \times c_{t}+e_{i, t}, e_{i, t} \sim$ i.i.d.N $\left(0, \sigma_{i}^{2}\right)$} \\
\hline$c_{t}=\emptyset \times c_{t-1}+v_{t}, v_{t} \sim$ i.i.d.N $\left(0, \sigma_{v}^{2}\right)$ \\
\hline$\alpha_{c}$ & Estimate & Standard error \\
\hline$\alpha_{p}$ & $0.866^{* * *}$ & 0.014 \\
\hline$\sigma_{c}^{2}$ & $0.832^{* * *}$ & 0.006 \\
\hline$\sigma_{p}^{2}$ & $0.961^{* * *}$ & 0.005 \\
\hline
\end{tabular}

Note: ${ }^{* *}$ indicate significance at $1 \%$ level.

Based on the results of Table 6 and Table 7, this paper constructs the unobserved component (permanent trends plus transitory cycles) model as a synthesizing model of common stochastic trend and dynamic factor models. That is, this paper recommends the use of the unobserved component (permanent trends plus transitory cycles) model rather than the separate uses of common stochastic trend model and dynamic factor model. Its estimation result is shown in Table 8. For the normalization of model, the variances of the shocks in the state equation $\sigma_{v, x}^{2}$ and $\sigma_{v, c}^{2}$ is set to be 0.0001 , respectively. All the measures of synchronicities of common stochastic trend and dynamic factor $\left(\gamma_{c}, \gamma_{p}, \alpha_{c}\right.$ and $\left.\alpha_{p}\right)$ are very significant. In addition, it is notable that the persistence degree of the autoregressive process of stationary factor $(\varnothing)$ is 0.989 , which is higher than simple dynamic factor model in Table 7. However, the variance of idiosyncratic component in Panamax market $\left(\sigma_{p}^{2}\right)$ is very close to zero. 
Table 8. Estimation Result of Unobserved Component Model

\begin{tabular}{|c|c|c|}
\hline \multicolumn{3}{|c|}{$\begin{array}{c}\operatorname{lny}_{i, t}=\gamma_{i} \times x_{t}+\alpha_{i} \times c_{t}+e_{i, t}, e_{i, t} \sim \text { i.i.d. } N\left(0, \sigma_{i}^{2}\right) \\
x_{t}=x_{t-1}+v_{x, t}, v_{x, t} \sim \text { i.i.d.N }\left(0, \sigma_{v, x}^{2}\right) \\
c_{t}=\emptyset \times c_{t-1}+v_{c, t}, v_{c, t} \sim \text { i.i.d.N } N\left(0, \sigma_{v, c}^{2}\right)\end{array}$} \\
\hline- & Estimate & Standard error \\
\hline$\varnothing$ & $0.989 * * *$ & 0.001 \\
\hline$\gamma_{c}$ & $0.931^{* * *}$ & 0.007 \\
\hline$\gamma_{p}$ & $0.921^{* * *}$ & 0.008 \\
\hline$\alpha_{c}$ & $0.984^{* * *}$ & 0.004 \\
\hline$\alpha_{p}$ & $0.823^{* * *}$ & 0.014 \\
\hline$\sigma_{c}^{2}$ & 0.188 & - \\
\hline$\sigma_{p}^{2}$ & 0.000 & - \\
\hline
\end{tabular}

Note: ${ }^{* * *}$ indicate significance at $1 \%$ level.

Based on the estimation result of Table 8 , we can estimate the unobserved stochastic trend and cyclical factor. This paper calculates the so-called smoothed estimates of these two unobserved variables by using the full sample information and corresponding smoothing algorithm (see Kim and Nelson, pp.27-28), which is shown in Figure 3. As shown, the permanent trend $\left(x_{t}\right)$ and transitory factor $\left(c_{t}\right)$ move together.

Figure 3. Evolutions of Stochastic Trend and Cyclical Factor

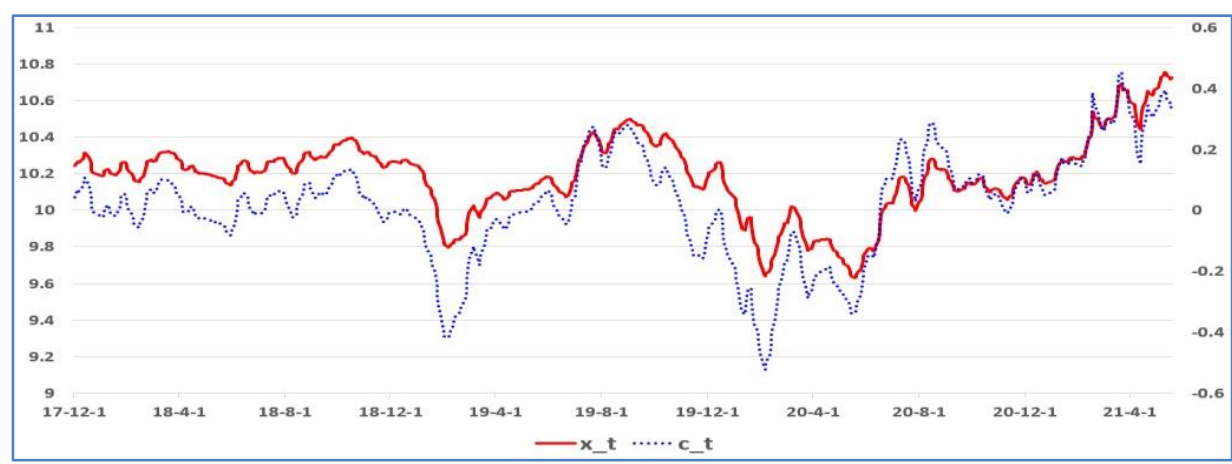

Note: $x_{-} t$ is the permanent trend and $c_{-} t$ is the transitory factor. 
As discussed in Ko (2010a), the unobserved component model may suffer from parameter instability problem. Figure 4 to Figure 6 show the evolutions of the parameter estimates, rolling the estimation in the way, in which the sample consists of 12 months (one year) and thus depleting the first observation and adding the new last one. The choice of one year as the period of parameter rolling estimation is due to the fact that there is seasonality concern in more frequency cases, e.g., quarterly, monthly, etc. Overall, there seems to have been parameter instability. According to Stock and Watson (2016), in coping with this parameter instability, there could be two different approaches. First is to incorporate the break times in the considered model and another is to model time-varying parameters structure.

Figure 4. Evolutions of $\emptyset, \gamma_{c}$, and $\gamma_{p}$

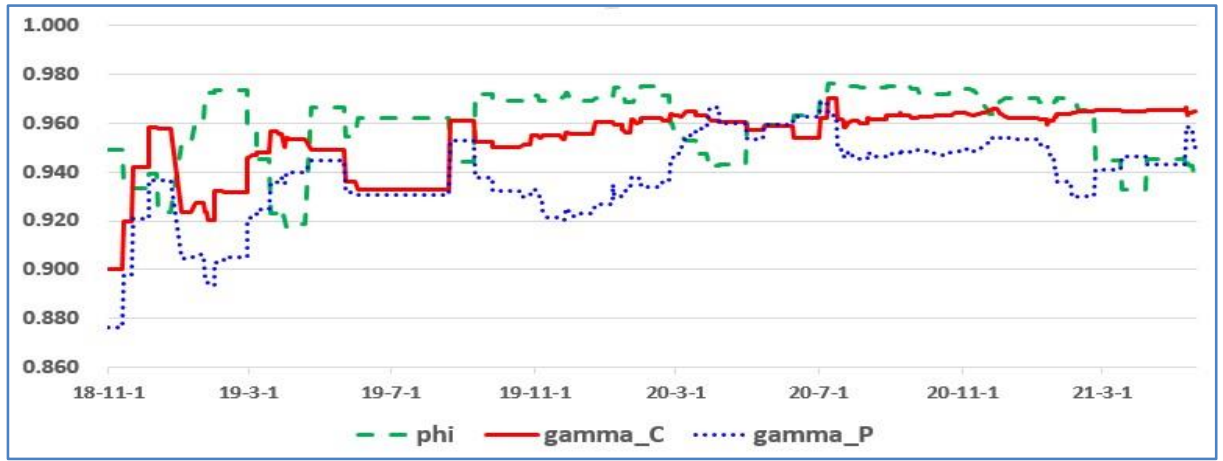

Figure 5. Evolutions of $\alpha_{c}$ and $\alpha_{p}$

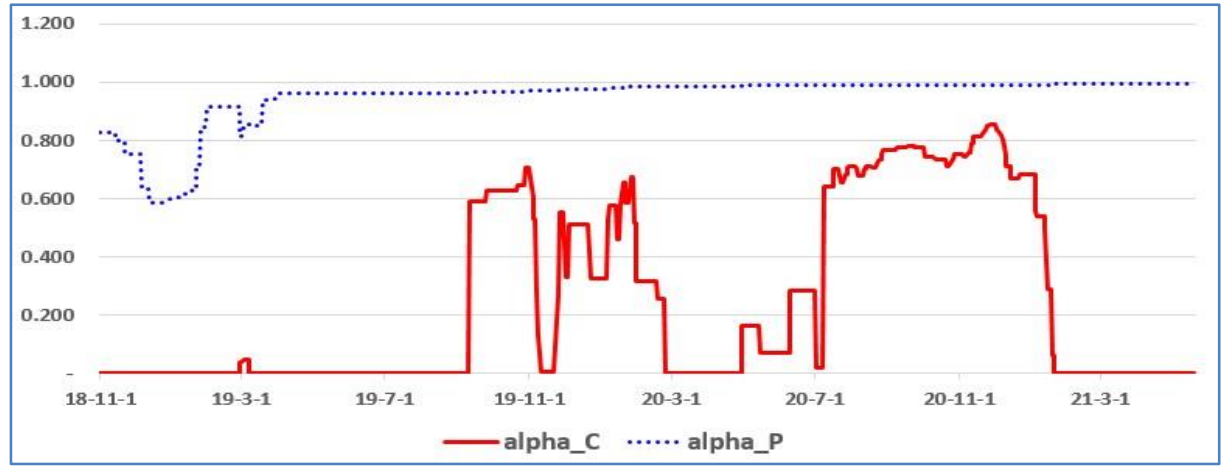


Figure 6. Evolutions of $\sigma_{c}^{2}$ and $\sigma_{p}^{2}$

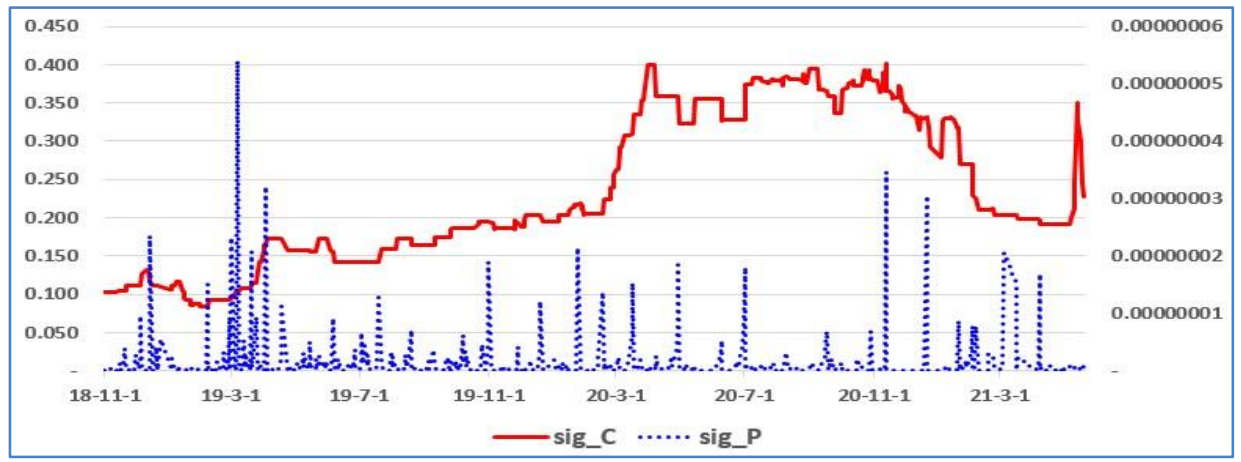

\section{Conclusions}

Based on the data of dry bulk shipping markets, this paper considers the three dynamic linear models such as common stochastic trend, dynamic factor, and unobserved component models by using state-space approach. All these dynamic linear models enable us to analyze the synchronicity and idiosyncrasy in the Capesize and Panamax freight markets in a coherent and efficient way. In particular, an unobserved component model, which incorporates the common stochastic trend and dynamic factor models, is proposed as a synthesizing approach. Using this unobserved component model, we can estimate the unobserved stochastic trend and dynamic factor via the Kalman filter and smoothing filter. This empirical investigation will help for the participants in dry bulk shipping markets to enhance the management efficiency of their revenues and market risks. In addition, this paper discusses the parameters instability problem by rolling the estimations whose sample consists of one year daily observations.

There remain three avenues for future research. First, based on the statistical significance of the dynamic linear models proposed in this paper (esp., unobserved component model), it will be possible to apply them to the more practical exercises, for example, forecasting the future rates. One of the causes of forecasting improvement would be the decomposition into the permanent and transitory components. More is there transitory elements, more successful is the forecasting. This is from the fact that by definition, the transitory components have a tendency to regress to the stationary expected value. That is, this tendency makes predictability. In contrast, the permanent components with random walk process, by its nature, are hard to predict. In other words, if we measure the transitory components, whether common or idiosyncratic, then by using this information, we can forecast the future direction of the considered variable conditioning on the recent information. 
Second, the parameter instability shown in Figures 4-6 should be studied. This paper recommends that the first step is to model the variation of parameter values as an evolving process over time and, the second step is to incorporate break points if there is sudden change of parameter values. However, if it is recommended to model these breaks, state-space model with Markov switching regimes would be an excellent method, whose estimation can be done efficiently via the Kim filter (see Kim, 1994 and Kim and Kang, 2019).

Third, it would be promising to investigate more structural characteristics of dry bulk shipping markets based on the reduced-form analyses of this paper. If the above second future research about the structural breaks in parameter values would provide some acceptable estimates on the break timings, then the comparisons among the different regimes would enable us to more understand the relevant markets. This enhancement of knowledge on the market dynamics will help the participants in dry bulk shipping markets to manage their revenues, cost, or market risks.

As a final remark, the recommended model for the dry bulk shipping freight rate movements by using some synthesizing unobserved component model with time-varying coefficients can be a good indicator for the decision making on the chartering strategies of shipowners or charterers. Furthermore, more investigation of structural characteristics of dry bulk shipping markets based on this model could yield fruitful information for the market participants and relevant policy makers.

\section{Acknowledgments}

The views expressed in this paper are those of the authors and do not reflect the official policy or position of the Korea Maritime Institute. This paper has largely benefited from the helpful comments and suggestions of the Editor and three anonymous referees.

\section{Disclosure Statement}

No potential conflict of interest was reported by the authors.

\section{Funding}

This research was supported by the Korea Maritime Institute, Republic of Korea. 


\section{References}

Adland, R., Benth, R. E. and Koekebakker, S. (2018) Multivariate modeling and analysis of regional ocean freight rates, Transportation Research Part E 113 : 194-221.

Alizadeh, A. H. and Nomikos, N. K. (2010) An overview of the dry bulk shipping industry, in Grammenos, C. Th. (ed.) The Handbook of Maritime Economics and Business, Lloyd's List : 319-353.

Angelopoulos, J., Sahoo, S. and Visvikis, I. D. (2020) Commodity and transportation economic market interactions revisited: New evidence from a dynamic factor model, Transportation Research Part E 133 : 101836.

Bai, J. (2004) Estimating cross-section common stochastic trends in nonstationary panel data". Journal of Econometrics 122 : 137-183.

Barigozzi, M. and Luciani, M. (2017) Common factors, trends, and cycles in large datasets, FEDS 2016-18, Board of Governors of the Federal Reserve System.

Barigozzi, M., Lippi, M. and Luciani, M. (2016a) Dynamic factor models, cointegration, and error correction mechanisms, FEDS 2016-18, Board of Governors of the Federal Reserve System.

Barigozzi, M., Lippi, M. and Luciani, M. (2016b) Non-stationary dynamic factor models for large datasets, FEDS 2016-24, Board of Governors of the Federal Reserve System.

Chang, Y., Miller, J. I. and Park, J. Y. (2009) Extracting a common stochastic trend: Theory and some applications, Journal of Econometrics 150 : 231-247.

Chen, S., Meersman, H. and Voorde, E. (2010) Dynamic interrelationships in returns and volatilities between Capesize and Panamax markets, Maritime Economics \& Logistics 12 : 65-90.

Clark, P. K. (1987) The cyclical component of U.S. economic activity, Quarterly Journal of Economics 102 : 797-814.

Clark, P. K. (1989) Trend reversion in real output and unemployment, Journal of Econometrics 40 : 15-32.

Dickey, D. and Fuller, W. A. (1979) Distribution of the estimators for autoregressive time series with a unit root, Journal of the American Statistical Association 74 : 427-431.

Dickey, D. and Fuller, W. A. (1981) The likelihood ratio statistics for autoregressive time series with a unit root, Econometrica 49 : 1057-1072.

Geweke, J. (1977) The dynamic factor analysis of economic time series. in Aigner, D. and A. Goldberger (eds) Latent Variables in Socio-Economic Models, North-Holland.

Johansen, S. (1995) Likelihood-based Inference in Cointegrated Vector Autoregressive Models, Oxford University Press.

Kalman, R. E. (1960) A new approach to linear filtering and prediction problem, 
Transactions ASME Journal of Basic Engineering D82 : 35-45.

Kim, Y. M. and Kang, K. H. (2019) Likelihood inference for dynamic linear models with Markov switching parameters: on the efficiency of the Kim filter, Econometric Reviews 38(10) : 1109-1130.

Kim, C. J. (1994) Dynamic linear models with Markov-switching, Journal of Econometrics $60: 1-22$.

Kim, C. and Nelson, C. (1999) State-Space Models with Regime Switching: Classical and Gibbs-Sampling Approaches with Applications, The MIT Press.

Ko, B. W. (2011a) An application of dynamic factor model to dry bulk market - Focusing on the analysis of synchronicity and idiosyncrasy in the sub-markets with different ship size -, KMI International Journal of Maritime Affairs and Fisheries 3(1) : 069082 .

Ko, B. W. (2011b) Dynamics of dry bulk freight market: Through the lens of a common stochastic trend model, The Asian Journal of Shipping and Logistics, 27(3) : 387404.

Mackinnon, J. G. (1996) Numerical distribution functions for unit root and cointegration tests, Journal of Applied Econometrics 11 : 601-618.

MacKinnon, J.G., Haug, A. A. and Michells, L. (1999) Numerical distribution function of likelihood ratio tests for cointegration, Journal of Applied Econometrics 14 : 563577.

Peña, D. and Poncela, P. (2006) Nonstationary dynamic factor analysis, Journal of Statistical Planning and Inference 136 : 1237-1257.

Stigler, S. M. (1986) The History of Statistics: The Measurement of Uncertainty before 1900, The Belknap Press of Harvard University Press.

UNCTAD. (2017) Review of Maritime. Transport 2017, United Nations Publication.

Stock, J. H. and Watson, M. W. (1988) Testing for common trends, Journal of the American Statistical Association 83(404) : 1097-1107.

Stock, J. H. and Watson, M. W. (2016) Dynamic factor models, factor-augmented vector autoregressions, and structural vector autoregressions in macroeconomics, Handbook of Econometrics Volume 2A : 415-525.

Veenstra, A. W. and Franses, P. H. (1997) A co-integration approach to forecasting freight rates in the dry bulk shipping sector," Transportation Research Part A: Policy and Practice 31(6) : 447-458.

Watson, M. W. (1994) Vector autoregressions and cointegration", in Engle, R. F. and D. L. McFadden (eds.) Handbook of Econometrics Volume IV, Elsevier Science B.V. : 2843-2915. 


\section{Appendix. Basic understanding of the state-space model}

We see the world. Further we can measure many things, whether they are physical or social. However, when measuring it, we encounter some uncertainties. State-space model and its estimation algorithm provide us with a powerful tool to deal with these uncertainties. In particular, there are numerous examples of unobserved important variables in social sciences. For example, in economics, the unobserved potential GDP (Gross Domestic Products) should be estimated from the observed GDP. The natural rate of unemployment is also an unobserved variable to be estimated from the observed unemployment data.

Suppose that the unobserved variable(s) is defined as $\beta_{t}$. We call this as the state variable in the sense that $\beta_{t}$ represents the hidden state of the considered world at the time $t$. Next, this state variable determines (or influences) the observed variable, $y_{t}$. This determination mechanism is modeled as $y_{t}=H \beta_{t}$. However, due to some causes such as measurement errors ( $E_{t}$ denoted in the below equation), we can state this mechanism as an uncertain regression equation as follows:

[Measurement Equation]

$$
y_{t}=H \beta_{t}+E_{t} \text {. }
$$

The above equation is called as the "measurement equation", which links the unobserved state variable $\beta_{t}$ with the observed variable $y_{t}$, through the coefficient $H$, including the measurement error $E_{t}$.

However, the state-space model incorporates the hidden dynamics of the state variable(s). Typically, this dynamics is assumed to have an autoregressive process of order 1 (hereafter AR(1)). Though not shown in detail, any autoregressive process of $\mathrm{k}$ orders $(\mathrm{k}=2,3,4, \ldots)$ can be represented by the $\mathrm{AR}(1)$ process. That is, the state variable is governed by the following state equation (or transition equation) with the form $\operatorname{AR}(1)$ :

[State (or Transition) Equation]

$\beta_{t}=F \beta_{t-1}+V_{t}$.

The parameter(s) which governs the dynamics of state variable(s) is $F$.

The parameters can be estimated by the maximum likelihood estimation and, at the same time, the hidden state variable(s) are estimated through the Kalman filter and smoothing algorithm. For more technical explanations for its underlying idea and estimation, refer to Kim and Nelson (1999). 